\title{
Decreased Hypoxia-Inducible Factor-1 $\alpha$ in Gastrocnemius Muscle in Rats with Chronic Kidney Disease
}

\author{
Mariusz Flisińskia Andrzej Brymora ${ }^{a} \quad$ Irena Bartłomiejczyk ${ }^{d} \quad$ Ewa Wiśniewska $^{b}$

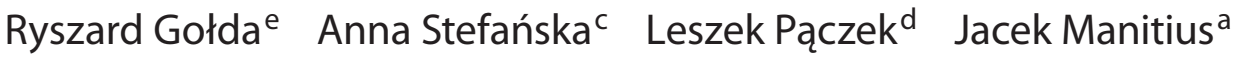 \\ Departments of ${ }^{a}$ Nephrology, Hypertension and Internal Diseases, ${ }^{b}$ Clinical Pathomorphology, and \\ ${ }^{c}$ Clinical Chemistry, Collegium Medicum of Nicolaus Copernicus University in Toruń, Bydgoszcz, \\ ${ }^{\mathrm{d}}$ Department of Immunotherapy, Transplantology and Internal Diseases, Medical University of Warsaw, Warsaw, \\ and ${ }^{\mathrm{e}}$ Institute of Experimental Biology, Kazimierz Wielki University in Bydgoszcz, Bydgoszcz, Poland
}

\section{Key Words}

Hypoxia-inducible factor- $1 \alpha \cdot$ Locomotor muscles $\cdot$ Chronic kidney disease $\cdot$ Rats

\begin{abstract}
Background/Aims: Hypoxia-inducible factor (HIF)-1 $\alpha$ is responsible for increased expression of genes engaged in angiogenesis. Our previous study indicated capillary rarefaction and atrophy of glycolytic fibers, mainly in locomotor muscles of uremic animals. Perhaps these changes are secondary to disturbances of HIF-1 $\alpha$ in skeletal muscles. Methods: Expression of HIF-1 $\alpha$ at mRNA and protein levels, as well as mRNA of vascular endothelial growth factor A (VEGF-A), vascular endothelial growth factor receptor (VEGFR)-1, VEGFR-2, endothelial nitric oxide synthase (eNOS) and inducible nitric oxide synthase (iNOS), in gastrocnemius muscle (MG) and longissimus thoracic muscle (ML) were measured by RTPCR and Western blot. Rats were randomized to subtotal nephrectomy (CKD5/6), uninephrectomy (CKD1/2) or sham operation (controls). Results: For CKD5/6 versus controls, mRNA levels for HIF-1 $\alpha$, VEGF-A, VEGFR-1 and VEGFR-2 were significantly reduced only in MG, while eNOS was significantly decreased and iNOS was significantly increased only in ML.
\end{abstract}

Western blot analysis indicated significantly increased HIF$1 \alpha$ protein levels in MG and ML from CKD1/2 animals versus controls, whereas in the CKD5/6 group, the level of HIF- $1 \alpha$ protein decreased significantly in MG and increased significantly in ML versus controls and CKD1/2. Conclusion: The reduced expression of HIF-1 $\alpha$ mRNA and protein in locomotor muscle from CKD5/6 animals may be involved in the pathogenesis of uremic myopathy. Increased expression of iNOS in the postural muscles may act as a protective factor through HIF- $1 \alpha$ stabilization.

Copyright $\odot 2012$ S. Karger AG, Basel

\section{Introduction}

Chronic kidney disease (CKD) is associated with many metabolic disturbances and with structural alteration of skeletal muscles which leads to extreme fatigue and progressive loss of skeletal muscle mass [1]. The main factors responsible for uremic myopathy syndrome seem to be chronic tissue hypoxia [2] and a chronic microinflammatory state which stimulates skeletal muscle protein breakdown through tumor necrosis factor- $\alpha$ (TNF- $\alpha)$ [3]. Cells of most organisms require oxygen to produce adequate

\section{KARGER \\ Fax +4161306 1234 \\ E-Mail karger@karger.ch}

www.karger.com (c) 2012 S. Karger AG, Basel

$1420-4096 / 12 / 0356-0608 \$ 38.00 / 0$

Accessible online at:

www.karger.com/kbr
Mariusz Flisiński, MD

Ul. Skłodowskiej-Curie 9

PL-85094 Bydgoszcz (Poland)

Tel. +48525854030

E-Mail flis3@wp.pl 
amounts of ATP necessary for metabolic processes. Hypoxia in CKD occurs within skeletal muscle cells mainly due to anemia, limited oxygen transfer from the capillaries to the mitochondria $[4,5]$ and, as we had shown in our previous study, a poor muscle microcirculatory network [6]. It has been found that the whole-body maximal oxygen consumption in CKD is about half of that for normal individuals, even after correction of anemia $[4,7]$. Depending on the severity of hypoxia, permanent damage to tissues and cells may occur. Changing oxygen levels can result in activation or suppression of certain homeostatic regulatory genes, allowing for the survival of tissues and cells despite fluctuating environmental conditions. The master regulator of transcriptional responses to hypoxia is hypoxia-inducible factor 1 (HIF-1) $[8,9]$. The activity of HIF-1 is markedly increased when the intracellular oxygen tension falls, resulting in transactivation of genes containing a hypoxia response element. HIF-1 is a heterodimer of inducible $\alpha$ and constitutively expressed $\beta$ proteins. HIF-1 $\alpha$ isoforms are relatively stable in hypoxia, but they have a half-life of about $5 \mathrm{~min}$ in the presence of oxygen. Following oxygen-dependent enzymatic hydroxylation of two distinct proline residues by prolyl hydroxylases, HIF-1 $\alpha$ binds von-Hippel-Lindau tumor suppressor protein, which leads to ubiquitination and degradation by the $26 \mathrm{~S}$ proteosome [10]. Hydroxylase inhibition in hypoxia leads to a rapid stabilization of HIF- $1 \alpha$ with a subsequent increase in HIF-1 target gene expression. HIF- $1 \alpha$ protein is detectable in skeletal muscles even in a normoxic or resting state, suggesting that HIF- $1 \alpha$ is necessary also for basal expression of genes responsible for cell homeostasis [11]. Its expression differs between fiber types, with the more glycolytic muscles showing constitutively higher HIF-1 $\alpha$ levels than the more oxidative ones [12]. HIF-1 is a principal regulator of oxygen homeostasis within cells. As a transcription factor, it affects and regulates the expression of dozens of genes involved in maintaining homeostasis as oxygen concentrations vary [13]. One of the first known functions of HIF-1 is activation of genes whose protein products induce erythropoiesis, but it has other important functions such as promotion of angiogenesis, modulation of vascular tone, glucose uptake, regulation of anaerobic metabolism in muscle glycolytic fibers and regulation of muscle mass, fiber transformation and cell death or survival $[8,12]$. A recent study performed by Hagström et al. [14] showed that the gastrocnemius muscle (MG) possesses a remarkable ability to develop its microvessel network to compensate for erythropoietin deficiency-induced anemia. Therefore, erythropoietin deficiency alone is not sufficient to explain muscle decon- ditioning in patients suffering from renal failure [14]. Ameln et al. [15], in a model of acute hypoxia (exercise and restricted blood flow to muscles) demonstrated that HIF$1 \alpha$ mRNA levels did not change while HIF-1 $\alpha$ protein levels increased in human skeletal muscle in response to acute changes in oxygen demands. They believed that the observed upregulation in HIF- $1 \alpha$ protein levels mainly depended on posttranscriptional mechanisms [15]. In a model of chronic hypoxia, Vogt et al. [16] demonstrated an increase in HIF-1 $\alpha$ mRNA levels in humans when 6 weeks of exercise training were combined with hypoxic gas breathing. These results may indicate that chronic hypoxia secondary to renal anemia should trigger the process of angiogenesis in skeletal muscles in order to maintain adequate blood flow and nutrient delivery. Results of our previous experiments performed on rat locomotor and postural skeletal muscles in different stages of CKD showed that the process of capillary rarefaction starts in the early stages of CKD and that these disorders are more severe in locomotor muscles than postural ones. That study also showed that the process of capillary removal might be independent of the plasma concentration of angiogenic growth factors [6]. These data indicated that CKD should be seen as a state of impaired angiogenesis. To find out if angiogenesis disturbances are secondary to the inadequate response to hypoxia at the cellular level, we investigated the expression of HIF- $1 \alpha$ mRNA as well as HIF- $1 \alpha$ protein contents in functionally different skeletal muscles of rats with varying degrees of renal failure. We also analyzed the expression of genes engaged in the process of angiogenesis which are upregulated by hypoxia, both HIF-1 dependent, i.e. vascular endothelial growth factor A (VEGF-A), vascular endothelial growth factor receptor 1 (VEGFR-1) and inducible nitric oxide synthase (iNOS), as well as HIF-1 independent, i.e. vascular endothelial growth factor receptor 2 (VEGFR-2) and endothelial nitric oxide synthase (eNOS).

\section{Methods}

Animal Procedure and Tissue Preparation

Experiments were carried out on male Wistar rats with an initial body weight of $340 \pm 10 \mathrm{~g}$. They were housed in a temperatureand humidity-controlled environment on standard rat chow and tap water ad libitum. All procedures were in accordance with guidelines set by Local Institutional Animal Care and Use Committees (permission number 13/2007). Under sodium pentobarbital anesthesia (approx. $50 \mathrm{mg} / \mathrm{kg}$, intraperitoneal injection), animals underwent one-step surgical nephrectomy with special care to protect the adrenal glands. The control group, which comprised 8 animals, had a sham operation; during this procedure, the kid- 
neys were exposed, and then a renal capsule was removed. In the CKD1/2 group $(n=10)$, right nephrectomy was performed through a right flank incision. In the CKD5/6 group $(n=12)$, the right kidney and about $2 / 3$ of the left kidney cortex were removed. After 6 weeks of experiments, again under sodium pentobarbital anesthesia, the animals were weighed and then sacrificed by removing blood from the heart. About $15 \mathrm{ml}$ of blood were taken for laboratory tests. The renal function was assessed by serum creatinine, blood urea nitrogen concentration and estimation of endogenous creatinine clearance $(\mathrm{CrCl})$. The $\mathrm{CrCl}$ was calculated from the following equation: $\mathrm{CrCl}(\mathrm{ml} / \mathrm{min})=$ urine creatinine $(\mathrm{mg} / \mathrm{dl}) \times$ urine volume $(\mathrm{ml} / 24 \mathrm{~h})] /[$ serum creatinine $(\mathrm{mg} / \mathrm{dl}) \times 1,440(\mathrm{~min})]$. The concentration of blood urea nitrogen, creatinine in serum and 24-hour urine were measured using the Hitachi 912 automated clinical chemistry analyzer (Roche Diagnostics Ltd., Lewes, UK). The serum hemoglobin concentration was measured using Roche reagents with the Hitachi 912 analyzer. The homocysteine assay is a fluorescence polarization immunoassay for the quantitative measurement of total L-homocysteine in serum on the AxSYM System (Abbott). Monocyte chemoattractant protein (MCP)-1 in serum was determined with a commercially available monoclonal antibody against rat MCP-1 (Pierce Endogen) using a Labsystem Multiscan RC analyzer. Advanced glycation end products (AGEs) were measured by fluorescence spectroscopy. Serum samples were diluted 50 -fold in $\mathrm{PBS}$ with $\mathrm{pH}=7.4$. Fluorescence spectra (corrected for background) were recorded in a Fluoroscan Ascent FL (Labsystems) spectrometer at room temperature. When excitation was performed at $355 \mathrm{~nm}$, the maximum emission was found at $460 \mathrm{~nm}$ and expressed in arbitrary units, as previously described [17].

\section{RNA Isolation and cDNA Production}

Tissue samples were taken from the red portion of the medial head of the MG and the Th2-Th8 part of the longissimus thoracic muscle $(\mathrm{ML})$, which is the thoracic part of the longissimus dorsi muscle. The samples were immediately put into liquid nitrogen. Total RNA was isolated from muscle samples using an RNA Universal Tissue Kit and Proteinase K (Qiagen GmbH, Hilde, Germany). In order to isolate RNA and to assess the expression of iNOS, DNase treatment was used to remove genomic DNA. All homogenization procedures were performed on a Biorobot EZ1 (Qiagen) according to the manufacturer's instructions. Quality and quantity of RNA in all cases was assessed by Spectrophotometer Nano Drop ND-1000 UV/VIS (USA) relative absorbance at 260 versus $280 \mathrm{~nm}$. Reverse transcription to produce cDNA was performed using an Invitrogen SuperScript ${ }^{\mathrm{TM}}$ System for RT-PCR (Cat. No. 18080-051, Invitrogen, Carlsbad, Calif., USA) according to the manufacturer's instructions on a Thermomixer Comfort (Eppendorf AG, Hamburg, Germany). Briefly, $4 \mu \mathrm{g}$ of total RNA was reverse transcribed with random hexamer primers in a final volume of $20 \mu \mathrm{l}$. The reaction was carried out for $5 \mathrm{~min}$ at $65^{\circ} \mathrm{C}$. Subsequently, cDNA Synthesis Mix $(20 \mu \mathrm{l})$ was added to each tube and incubated as follows: $10 \mathrm{~min}$ at $25^{\circ} \mathrm{C}, 50 \mathrm{~min}$ at $50^{\circ} \mathrm{C}$ and 5 min at $85^{\circ} \mathrm{C}$. Finally, RNase $\mathrm{H}$ was added to each tube and incubated for $20 \mathrm{~min}$ at $37^{\circ} \mathrm{C}$.

Quantification of Gene Expression by TaqMan RT-PCR

The cDNA (proportional to mRNA) levels for HIF-1 $\alpha$ (assay ID Rn 00577560_m1), VEGF-A (assay ID Rn 00582935_m1), VEGFR-1 (assay ID Rn01409516_m1), VEGFR-2 (assay ID Rn 00564986_m1), eNOS (Rn 02132634_s1), iNOS (assay ID Rn 00561646_m1) and the housekeeping gene glyceraldehyde-3phosphate dehydrogenase (GAPDH; rat GAPDH 4352338E) were determined by a fluorescence-based RT-PCR on an ABI PRISM 7700 Sequence Detection System (Applied Biosystems, Foster City, Calif., USA). Primers were obtained from Applied Biosystems. Reactions were performed with an appropriate negative control, i.e. template-free control animals. The parameter threshold cycle (CT) was the fractional cycle number at which the fluorescence generated by cleavage of the probe exceeded a fixed threshold above the baseline. To evaluate the amount of target gene, the comparative CT method was used as outlined in Applied Biosystems User Bulletin No. 2 [18]. Firstly, the mean CT values of duplicate samples from each group were determined and normalized to expression of the endogenous control, GAPDH, by calculation of the change in CT $(\Delta \mathrm{CT})$ (sample) according to the following equation: $\Delta \mathrm{CT}$ (sample) $=$ average $\mathrm{CT}$ (sample) - average CT (GAPDH). $\Delta \mathrm{CT}$ (sample) was then related to $\Delta \mathrm{CT}$ of the experimental controls (sham operated) by computing $\Delta \Delta \mathrm{CT}$, where $\Delta \Delta \mathrm{CT}=\Delta \mathrm{CT}(\mathrm{CKD} 5 / 6$ or $\mathrm{CKD} 1 / 2)-\Delta \mathrm{CT}$ (sham). The amount of target amplification relative to the experimental control was calculated by the formula $2^{-\Delta \Delta C T}$. In the comparative CT method, gene expression of the control group is a reference point for the analyzed groups and is always equal to one. Thus, all experimental samples were expressed as the $n$-fold difference relative to the control.

\section{Western Blot Analysis of HIF-1 $\alpha$ Protein}

The excised muscle tissue $(100 \mathrm{mg}$ ) was homogenized in a manual glass-Teflon homogenizer. The resulting slurry was dissolved in lysis buffer ( $8 \mathrm{~mm}$ urea, 1/10 v/v glycerol, 1/20 v/v 20\% SDS, $1 / 200 \mathrm{v} / \mathrm{v} 11 \mathrm{mM}$ DTT, $1 / 100 \mathrm{v} / \mathrm{v} 0.5 \mathrm{~mm}$ Tris, $\mathrm{pH}$ 6.8) with the addition of a mixture of protease inhibitor cocktail (Complete Mini, Roche) and centrifuged at $15,000 \mathrm{rpm}$ for $30 \mathrm{~min}$ at $4^{\circ} \mathrm{C}$. All protein concentrations were determined with the Bio-Rad Laboratories DC protein assay kit, based on the method of Lowry. Isolated proteins were mixed with Roto-Load1 sample buffer (Roth), which contains phosphate buffer, SDS (approx. 8\% v/v), glycerol (approx. 40\% v/v), mercaptoethanol (approx. 20\% v/v) and bromophenol blue (approx. $0.015 \% \mathrm{v} / \mathrm{v}$ ), and incubated at $95^{\circ} \mathrm{C}$ for $8 \mathrm{~min}$. Equal amounts of protein $(25 \mu \mathrm{g})$ were loaded in each lane, separated by $10 \%$ SDS-PAGE, transferred onto a $0.45-\mu \mathrm{m}$ nitrocellulose membrane (162-0094, Bio-Rad) and air-dried. Molecular weight marker (161-0373, Bio-Rad) Precision Plus Protein Standards (Bio-Rad) was loaded into a separate lane.

The nitrocellulose sheets were then blocked in TBST buffer (10 mM Tris- $\mathrm{HCl}, 150 \mathrm{mM} \mathrm{NaCl}, 0.05 \%$ Tween, $\mathrm{pH}$ 7.4) supplemented with $5 \%$ bovine serum albumin (BSA; Sigma-Aldrich) for $2 \mathrm{~h}$ at room temperature. Incubation with mouse anti-HIF-1 $\alpha$ monoclonal antibody (ab1, Abcam) or mouse anti- $\beta$-actin monoclonal antibody (A1978, Sigma-Aldrich; diluted 1:700 and 1:3,000 in TBST with $1 \%$ BSA, respectively) was carried out for $16 \mathrm{~h}$ at $4{ }^{\circ} \mathrm{C}$ and followed by 8 washings in TBST for $2 \mathrm{~h}$ at room temperature. The blots were subsequently incubated for $1 \mathrm{~h}$ with secondary antimouse antibody coupled to alkaline phosphatase (A4312, Sigma-Aldrich) that was diluted 1:5,000 in TBST with 1\% BSA. After several washings in TBST buffer and AP buffer $(100 \mathrm{mM}$ Tris- $\mathrm{HCl}$, $100 \mathrm{~mm} \mathrm{NaCl}, \mathrm{pH}$ 8.5), the blots were incubated with 5-bromo-4chloro-3-indolyl phosphate/nitro blue tetrazolium for $5 \mathrm{~min}$. The reaction was stopped by dipping the blots in distilled water. 
Table 1. The experimental data

\begin{tabular}{lccc}
\hline Parameters & Controls $(\mathrm{n}=8)$ & CKD1/2 $(\mathrm{n}=10)$ & CKD5/6 $(\mathrm{n}=12)$ \\
\hline Weight gain, g & $115 \pm 30$ & $63 \pm 30^{\mathrm{a}}$ & $33 \pm 33^{\mathrm{a}, \mathrm{b}}$ \\
BUN, mg/dl & $28.07 \pm 4.0$ & $29.48 \pm 3.61$ & $63.88 \pm 17.85^{\mathrm{a}, \mathrm{b}}$ \\
Creatinine, mg/dl & $0.83 \pm 0.27$ & $0.74 \pm 0.07$ & $1.22 \pm 0.24^{\mathrm{a}, \mathrm{b}}$ \\
CrCl, ml/min/100 g body weight & $0.50 \pm 0.02$ & $0.39 \pm 0.06^{\mathrm{a}}$ & $0.26 \pm 0.09^{\mathrm{a}, \mathrm{b}}$ \\
Hemoglobin, g/dl & $14.1 \pm 1.0$ & $13.75 \pm 0.75^{\mathrm{a}}$ & $11.45 \pm 3.1^{\mathrm{a}}$ \\
L-Homocysteine, $\mu \mathrm{M}$ & $4.95 \pm 0.58$ & $5.18 \pm 0.55$ & $7.26 \pm 1.19^{\mathrm{a}, \mathrm{b}}$ \\
MCP-1, pg/ml & $292.5 \pm 113.9$ & $489.4 \pm 265.2^{\mathrm{a}}$ & $609.0 \pm 255.1^{\mathrm{a}}$ \\
AGEs, arbitrary units & $4.60 \pm 0.97$ & $4.27 \pm 1.19$ & $5.14 \pm 0.64^{\mathrm{b}}$ \\
\hline
\end{tabular}

BUN $=$ Blood urea nitrogen. ${ }^{a} \mathrm{p}<0.05$ for CKD1/2 and CKD5/6 groups compared to controls; ${ }^{b} \mathrm{p}<0.05$ for CKD5/6 group compared to CKD1/2 group.

In Western blot, antibodies recognized a protein of approximately $120 \mathrm{kDa}$, representing HIF-1 $\alpha$, and a protein of approximately $45 \mathrm{kDa}$, representing $\beta$-actin. Average protein expression was obtained using the GeneTools analysis software (Syngene).

\section{Statistical Analysis}

Data were determined by factorial analysis of variance, with intergroup comparisons assessed by Bonferroni's post hoc method. $\mathrm{p}<0.05$ was considered to be significant.

Data for mRNA expression are presented as the mean $\pm S D$ transcript amount relative to control values. HIF-1 $\alpha$ protein expression was quantified relative to $\beta$-actin expression and presented as the mean $\pm \mathrm{SD}$.

\section{Results}

The results of laboratory tests and weight gains are presented in table 1.

Calculation of $\mathrm{CrCl}$ confirmed significant differences in renal function among the examined groups $(0.50 \pm$ 0.02 vs. $0.39 \pm 0.06$ and $0.26 \pm 0.09 \mathrm{ml} / \mathrm{min} / 100 \mathrm{~g}$ of body weight for controls vs. CKD1/2 and CKD5/6, respectively; $\mathrm{p}<0.05)$. Rats from CKD groups showed a significantly decreased weight gain and hemoglobin concentration with deteriorating kidney function compared to control animals. Markers of inflammatory state, i.e. MCP-1, homocysteine and AGEs, increased significantly in CKD5/6 animals as compared with controls.

\section{Gene Expression}

Compared with control animals, expression of HIF$1 \alpha$, VEGF-A, VEGFR-1 and VEGFR-2 mRNA was reduced in locomotor muscle (MG) in rats with renal failure, but only in the CKD5/6 group did it reach statistical significance ( $p<0.05$; fig. 1$)$. In contrast, expression of
HIF-1 $\alpha$, VEGF-A, VEGFR-1 and VEGFR-2 mRNA was not significantly different among the examined groups in postural muscle (ML). Nevertheless, a tendency for higher expression of HIF- $1 \alpha$ and VEGF-A mRNA in ML was observed in CKD1/2 versus control and CKD5/6 animals (fig. 2).

The relative expression of eNOS mRNA decreased with deteriorating renal failure in both muscles, but this reached statistical significance only in ML of CKD5/6 rats. iNOS mRNA expression increased significantly with declining renal function in both muscles, but it was statistically significant only in ML of CKD5/6 animals (fig. 1-3).

\section{Western Blot}

Analysis of the relative band densities of HIF-1 $\alpha$ protein in control animals indicated about 10 times less HIF$1 \alpha$ protein in ML in comparison with MG. HIF-1 $\alpha$ protein was not in agreement with the HIF- $1 \alpha$ mRNA expression pattern in MG from CKD1/2 rats, nor in ML from CKD5/6 animals. HIF- $1 \alpha$ protein levels increased significantly in both examined muscles (MG and ML) in CKD1/2 animals as compared with controls, whereas in the CKD5/6 group, the levels of HIF-1 $\alpha$ protein behaved differently in the examined muscles, being significantly decreased in MG and significantly increased in ML as compared with the control and CKD1/2 groups (fig. 4).

\section{Discussion}

This study was conducted on the basis of previous experiments performed on rats with CKD induced by surgical kidney ablation [6]. Severe loss of capillaries in skeletal 


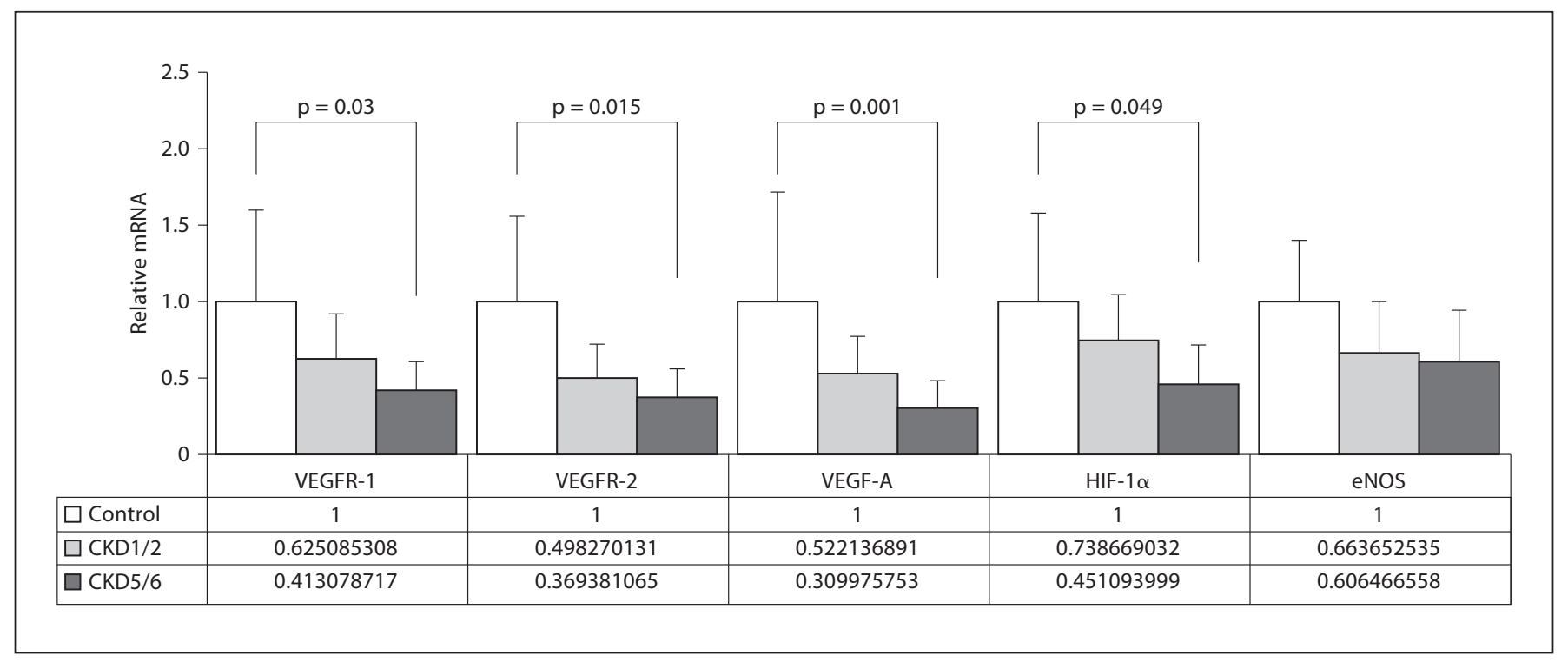

Fig. 1. Effect of CKD on VEGFR-1, VEGFR-2, VEGF-A, HIF-1 $\alpha$ and eNOS mRNA expression in MG. Relative mRNA expression levels were determined by real-time quantitative PCR. Values representing the amounts of mRNA were first normalized to GAPDH and then expressed relative to sham-operated controls. Error bars represent SDs.

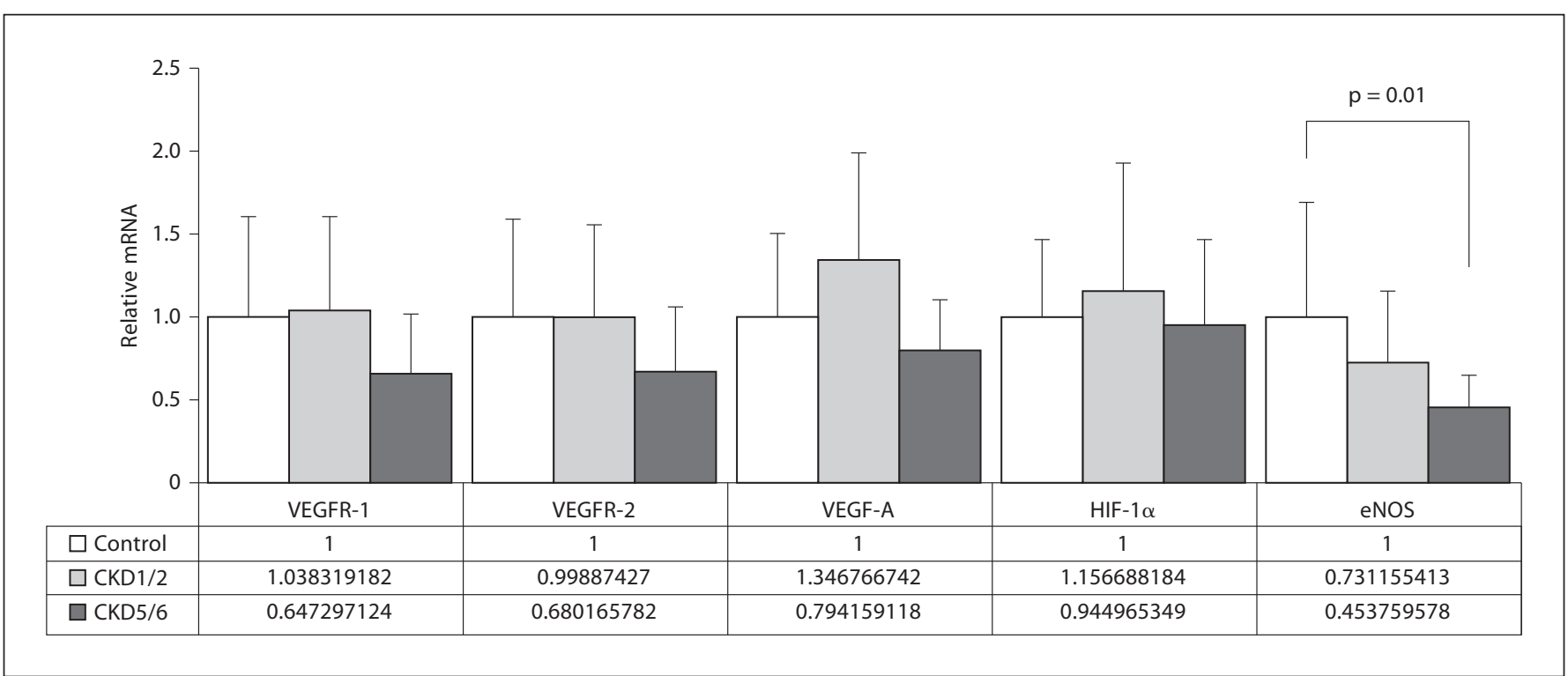

Fig. 2. Effect of CKD on VEGFR-1, VEGFR-2, VEGF-A, HIF-1 $\alpha$ and eNOS mRNA expression in ML. Relative mRNA expression levels were determined by real-time quantitative PCR. Values representing the amounts of mRNA were first normalized to GAPDH and then expressed relative to sham-operated controls. Error bars represent SDs. 


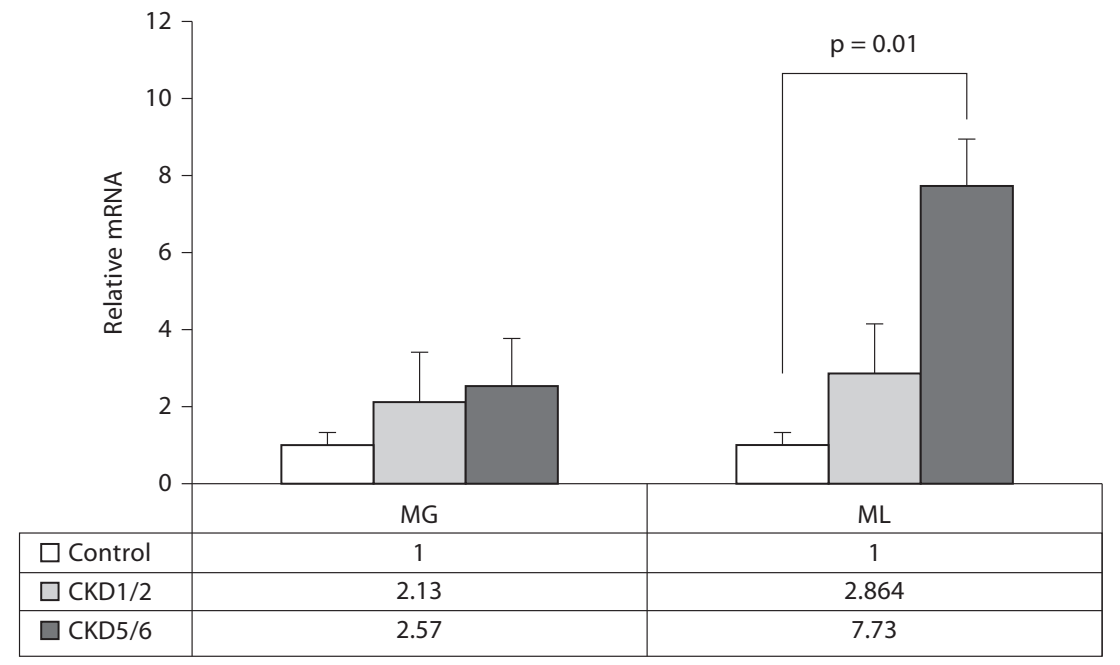

Fig. 3. Effect of CKD on iNOS mRNA expression in MG and ML. Relative mRNA expression levels were determined by real-time quantitative PCR. Values representing the amounts of mRNA were first normalized to GAPDH and then expressed relative to sham-operated controls. Error bars represent SDs.

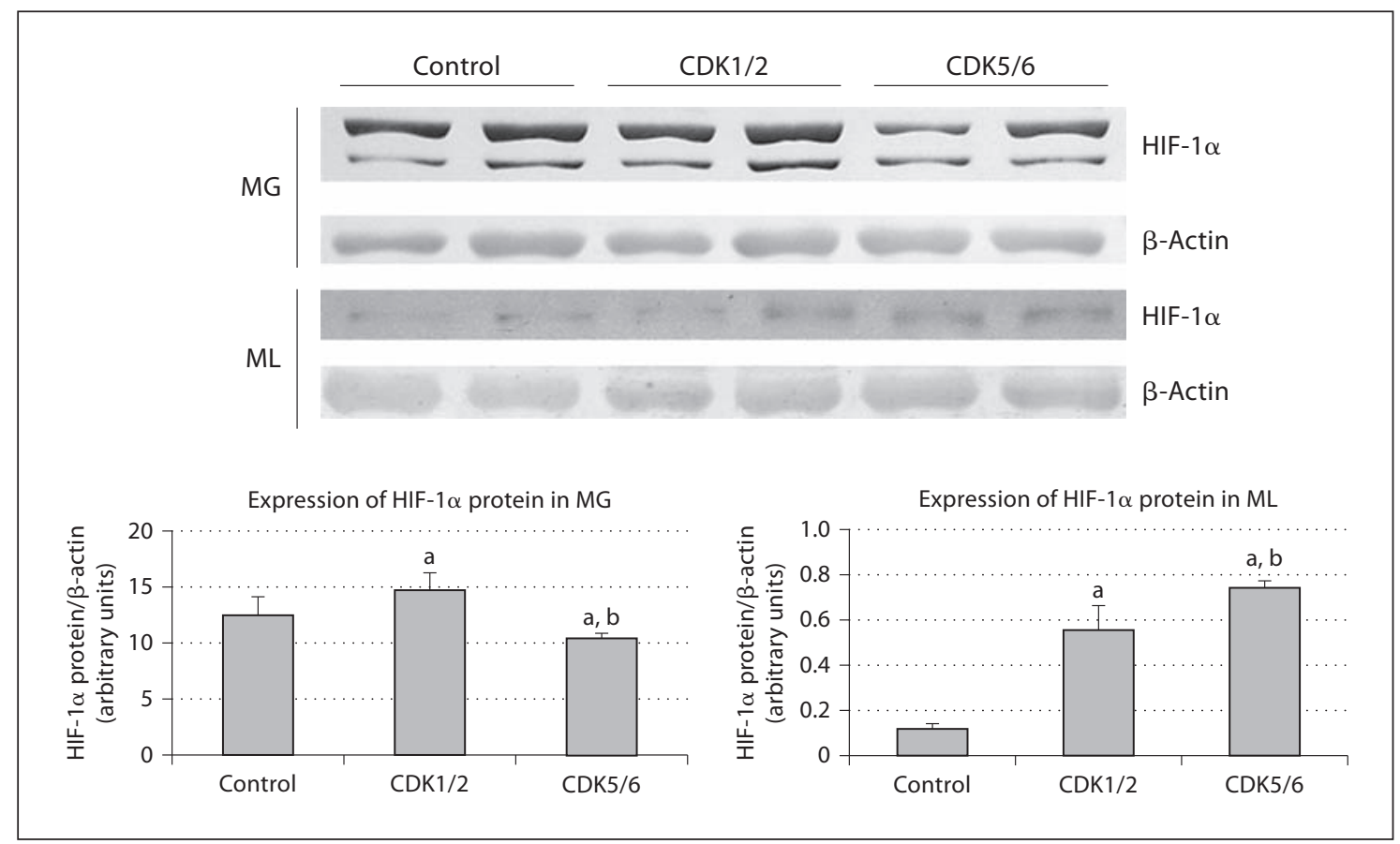

Fig. 4. Effect of CKD on HIF-1 $\alpha$ protein contents in MG and ML. Two representative immunoblot assays of HIF- $1 \alpha$ protein from each group were analyzed. Densitometric analyses of Western blots were performed. Data were normalized to $\beta$-actin. Values are presented as means \pm SD. ${ }^{\text {a }} \mathrm{p}<0.05$ for CKD groups versus control; ${ }^{\mathrm{b}} \mathrm{p}<0.05$ for CKD5/6 versus CKD1/2. 
muscles was observed. The decrease in capillary density was higher in locomotor muscle (MG; about 50\%) than in postural muscle (ML; about 30\%) in animals with CKD versus sham-operated animals. There was also a tendency for atrophy of muscle fibers in CKD5/6 animals, which was statistically significant only for glycolytic fibers. A tendency to reduced numbers of glycolytic fibers and increased numbers of oxidative ones in ML of CKD1/2 animals was also found (unpubl. data). We conclude that loss of capillaries could be associated with impaired angiogenesis in CKD secondary to a microinflammatory state and endothelium dysfunction, lower expression of proangiogenic factors at a cellular level or disuse atrophy associated with CKD (rats with renal failure are less active). In another study, we were surprised to learn that bone marrow-derived progenitor cells taken from CKD animals, even in early stages of CKD (CKD1/2 group), had lower viability and capacity for in vitro proliferation. The CD34primary cultures established from CKD1/2 and 5/6 rats collapsed within 2 weeks, while cells from control animals revealed normal fibroblast-like morphology of mesenchymal stem cells during a 3-month period [19]. It is well known that bone marrow-derived progenitor cells migrate to the site of endothelium damage and restore its function, so diminished viability of these cells might be an important factor in impaired angiogenesis in CKD.

In this work, we found significantly diminished expression of HIF- $1 \alpha$ mRNA, as well as mRNA of VEGF-A, VEGFR-1 and VEGFR-2, in locomotor muscle (MG) in advanced stages of CKD, i.e. the CKD5/6 group. We did not find significant differences in expression of these genes in postural muscle (ML), while a tendency for upregulation of HIF- $1 \alpha$ and VEGF-A mRNA in CKD1/2 animals was observed. We observed a different pattern of HIF-1 $\alpha$ protein expression in the analyzed muscles with deterioration of renal function. There was a significantly lower level of HIF- $1 \alpha$ protein in MG muscle of CKD5/6 animals as compared with controls. At the same time, there was about an 8 -fold higher level of HIF-1 $\alpha$ protein in $\mathrm{ML}$ of CKD5/6 as compared with controls. Interestingly, this increased HIF-1 $\alpha$ protein level in ML did not translate into increased mRNA expression of VEGF-A and VEGFR-1. At the same time, the expression of HIF$1 \alpha$ protein in CKD1/2 animals increased significantly in both examined muscles (MG and ML) as compared with controls.

These results may indicate an intact response to systemic hypoxia (renal anemia) through increased expression of HIF- $1 \alpha$ protein in skeletal muscle of animals with mild renal insufficiency (CKD1/2) and that this response may be altered primarily in locomotor muscle in more advanced stages of renal failure (CKD5/6). Increased expression of HIF- $1 \alpha$ protein in ML, which did not translate into an increased number of mRNA genes whose transcription is regulated by HIF- $1 \alpha$ protein (VEGF-A, VEGFR-1), may indicate that there is a disturbed response to hypoxia at the molecular level, also in postural muscles. Results from other authors, indicating that muscles with predominantly glycolytic fibers have higher expression of HIF-1 $\alpha$ compared with muscles with aerobic fibers, coincide with our results obtained in the control group. This confirms the important role of HIF-1 $\alpha$ in maintaining metabolism in skeletal muscle under aerobic conditions [12].

Despite the lack of statistically significant differences in the expression of HIF-1 $\alpha$ mRNA in both examined muscles in the CKD1/2 group relative to controls, a significant increase in HIF- $1 \alpha$ protein was found. This may confirm that HIF- $1 \alpha$ expression at the protein level under conditions of systemic hypoxia is regulated through a posttranslational modification mechanism, by inhibiting the hydroxylation of HIF- $1 \alpha$. Besides hypoxia, a variety of environmental factors such as inflammation, reactive oxygen species (ROS) or nitric oxide can induce HIF-1 $\alpha$ protein accumulation [20].

Skeletal muscle reveals a continuum of mechanical and metabolic properties from slow contractile speed slow oxidative or type I fibers, which have low fatigability, to fast contractile speed fast glycolytic or type IIb fibers, which have high fatigability. In slow oxidative fibers, energy is generally sustained by oxidative metabolism, while in fast glycolytic fibers, energy is mainly generated by glycolytic metabolism. The third type of fibers are fast oxidative glycolytic or IIA fibers, whose metabolism is intermediate between the other types. Differences in the oxidative capacity of type I and II fibers are mainly due to more marked capillarization, higher content of mitochondria and higher activity of oxidative enzymes in type I fibers. Moreover, this metabolic/mechanical status is not fixed but adapts to environmental changes such as chronic activity modifications [21]. In normoxic conditions, oxidative fibers have low HIF- $1 \alpha$ content and express a high level of myoglobin, which may form an intracellular oxygen reserve for oxygen supply. In contrast, glycolytic fibers express a low level of myoglobin and have high HIF- $1 \alpha$ content, which provide hypoxia protection for these fibers [11].

Recent evidence has demonstrated higher ROS production in skeletal muscle mitochondria, particularly from type II fibers compared with type I fibers [22]. 
Hypoxic cells paradoxically increase their mitochondrial production of ROS, leading to oxidative stress. Excess production of these free radicals and ROS in vivo has a variety of damaging effects which include membrane lipid peroxidation, protein oxidation and DNA degradation [23]. Considerable evidence exists for a role of ROS in stabilization of HIF-1 $\alpha$, particularly in low $\mathrm{O}_{2}$ environments. The activity of proline hydroxylases has been shown to be exquisitely sensitive to inhibition by ROS [22]. It has been shown that oxidative muscles have more robust expression and activity of antioxidant enzymes than glycolytic muscles, and there is less mitochondrial superoxide production in oxidative fibers than in glycolytic ones [22].

Yu et al. [24], in a mouse model of muscle wasting (after injection of endotoxin), confirmed a higher level of ROS generation and enhanced expression of muscle-specific proteins engaged in ubiquitination and proteosomedependent protein degradation in glycolytic rather than oxidative muscles. By contrast, NO production, iNOS and antioxidant gene expression (superoxide dismutase 3) were significantly enhanced in oxidative but not glycolytic muscles, suggesting that NO mediates protection against muscle wasting. These findings suggest that NOdependent upregulation of antioxidant genes, mediated by iNOS, protects oxidative fibers against ROS accumulation and secondary cellular damage. The morphometric analysis performed by our group revealed that ML has 38\% more slow oxidative fibers than MG (unpubl. data). This fact might explain the significantly increased iNOS expression in ML observed in our study.

Hypoxia exerts direct effects on NO signaling by its effects on nitric oxide synthase subtypes. It has been shown that hypoxia suppresses production of NO by the endothelium (eNOS) but upregulates iNOS in smooth muscle [25]. The results of eNOS and iNOS mRNA expression obtained by us in this study confirmed the above-mentioned observation.

Several reports have implied a role for NO in the regulation of HIF-1 $\alpha$; however, there are conflicting reports of both increases and decreases in the transcriptional activity of HIF-1 exerted by a variety of NO donors [25]. A direct role of ROS released by mitochondria has also been implied in the regulation of HIF- $1 \alpha$, but again reports are contradictory [26]. It was indicated that HIF-1 $\alpha$ could be activated in microvascular endothelial cells under conditions associated with massive $\mathrm{NO}$ production such as inflammation and ischemia-reperfusion. Protein phosphorylation events are involved in HIF-1 $\alpha$ activation during hypoxia and NO exposure [20], while ROS degrade the HIF-1 $\alpha$ subunit [27]. The physiological significance of NO in activating HIF-1 has been proven in experiments where expression of iNOS stabilized HIF- $1 \alpha$.

A study performed by Hagen et al. [28] confirmed that during hypoxia (exposure of cells to $3 \% \mathrm{O}_{2}$ ), low concentrations of NO (below $400 \mathrm{nM}$ ) facilitated rapid destruction of HIF- $1 \alpha$ and thus reversed HIF signaling, while high concentrations of $\mathrm{NO}(>1 \mu \mathrm{M})$ were able to stabilize HIF-1 $\alpha$ under both normoxia as well as hypoxia. Low levels of NO impaired mitochondrial respiration and redistributed oxygen towards nonrespiratory oxygen-dependent targets such as prolyl hydroxylases, so that they did not register hypoxia. The ability of high NO concentrations to stabilize HIF-1 $\alpha$ during hypoxia was not impaired by inhibition of mitochondrial respiration [27-29]. On the other hand, $\mathrm{NO}$ as a free radical reacts rapidly to ROS, particularly to superoxide anion, to create peroxynitrate, one of the most reactive compounds in nature. It has been confirmed that NO blocks HIF- $1 \alpha$ stabilization in the presence of superoxide anion donors or $\mathrm{H}_{2} \mathrm{O}_{2}$ [27]. Thus, ROS and NO may be able to activate HIF-1 $\alpha$ but, when they co-occur, they may react by forming compounds such as peroxynitrate, which lacks this ability and might cause HIF-1 $\alpha$ degradation. Köhl et al. [30] confirmed that intermediate concentrations of ROS produced by 2,3-dimethoxy-1,4-naphthoquinone attenuated HIF- $1 \alpha$ accumulation, which was mediated by an active proteasomal degradation pathway. They proposed that scavenging of NO by ROS attenuated HIF- $1 \alpha$ accumulation in a concentration-dependent manner [30]. Another study also indicated that delivering intracellular or extracellular $\mathrm{O}_{2}{ }^{-}$during $\mathrm{NO}$ generation resulted in a concomitant increase in oxidative intermediates, with a decrease in steady-state $\mathrm{NO}$ concentrations and a proportional reduction of $\mathrm{NO}$-evoked HIF-1 $\alpha$ stabilization. NO responses were restored by the addition of superoxide dismutase [31].

The diminished protein contents of HIF- $1 \alpha$ in MG found in our study could be explained by severe HIF- $1 \alpha$ breakdown due to high ROS generation by glycolytic fibers or increased activity of prolyl hydroxylases secondary to coexistence of a low level of NO with hypoxia. In ML, which has more oxidative fibers, stabilization of HIF-1 $\alpha$ through NO-dependent phosphorylation could occur with iNOS overexpression. Oxidative fibers possess an intact NO-dependent signalling and transcription system protecting these fibers from oxidative stress by enhancing the antioxidant system. CKD is associated with increased oxidative and carbonyl stress and diminished activity of antioxidant enzymes, so the increased 
HIF-1 $\alpha$ degradation through ROS and peroxynitrate might occur more predominantly in locomotor than postural muscles. These findings confirmed that postural muscle as opposed to locomotor muscle might be more resistant to hypoxia and atrophy secondary to CKD.

Interestingly, HIF- $1 \alpha$ itself may repress mitochondrial function and oxygen consumption by inhibiting pyruvate dehydrogenase, thereby preventing pyruvate from fueling the Krebs cycle, which again will result in a relative increase in intracellular oxygen tension [32]. Inducible NO synthase is an HIF- $1 \alpha$ target gene, and its upregulation under hypoxia may help to turn off the system. When NO inhibits mitochondrial respiration under hypoxia, it prevents mitochondria from depleting local oxygen, enabling the continued hydroxylation and degradation of HIF-1 $\alpha$, thus leading to a situation in which the cell may fail to register hypoxia [33].

Histochemical studies performed on vastus lateralis muscle biopsies from chronic uremic patients on maintenance hemodialysis therapy showed type II fiber atrophy, disruption of myofibrillar architecture and a statistically significant increase in subsarcolemmal deposits of glycogen and lipids [34]. In a study performed on 4-month-old mice with the skeletal muscle HIF-1 $\alpha$ gene knocked out, Mason et al. [35] revealed significantly greater amounts of muscle damage and increased intramuscular levels of glycogen in $\mathrm{MG}$ as compared with wild-type animals. These histological findings were correlated with significantly reduced exercise endurance. The muscle damage seen in HIF-1 $\alpha$ knockout muscles is similar to that detected in human disorders of defective glycogenolysis and glycolysis. Additionally, the expression of various proteins responsible for the regulation of muscle mass and cell death or survival, such as insulin-like growth factor (IGF)-II, IGF-binding proteins 1, 2 and 3 or p21, is also upregulated by HIF- $1 \alpha$. In a study performed in hemodialysis patients, Kopple et al. [36] showed significantly reduced mRNA levels for IGF-IEa, IGF-II and IGF-I receptor as compared with the sedentary control patients. They concluded that these abnormalities may contribute to the sarcopenia and disabled endurance capacity, strength and physical performance that occur in hemodialysis patients [36]. Patients with end-stage renal failure are exposed to an increased oxidative stress, as evidenced by decreased levels of the antioxidant system as well as increased ROS formation [37]. In patients with end-stage renal failure, the frequency of 4,977-bp deletions in the skeletal muscle tissue was enhanced significantly as compared with controls (77 vs. 22\%) [38]. In the pathogenesis of DNA damage, a plethora of factors could be involved such as enhanced ROS formation, lipid peroxidation products and hypomethylation. It has been shown that AGEs and reactive carbonyl compounds are markedly enhanced in end-stage renal failure. These uremic toxins not only cause progressive and irreversible modifications of proteins but also possess genotoxic potential. Ingrosso et al. [39] showed that hyperhomocysteinemia could be associated with altered gene expression, imprinting and genomic integrity through DNA hypomethylation [39]. Our study has also confirmed a significantly higher homocysteine concentration and tendency to higher level of AGEs in CKD5/6 versus control animals. These disturbances can contribute to DNA damage in CKD5/6 animals and the lack of response to hypoxia through an increase in the expression of genes responsible for the regulation of angiogenesis.

HIF-1 triggers a coordinated response of angiogenesis by inducing expression of VEGF, VEGFR-1, iNOS, platelet-derived growth factor and transforming growth factor- $\beta 1$. Also, mechanical forces such as shear stress modulate vascular function and remodelling by eNOS [40]. A study by Pajusola et al. [41] indicated that stabilized HIF$1 \alpha$ is superior to VEGF in inducing angiogenesis in skeletal muscles. Overexpression of VEGF led to increased numbers of endothelial cells, whereas HIF-1 $\alpha$ induced significant capillary proliferation and sprouting and was responsible for proper arrangement of endothelial cells into new capillary structures [41]. Jacobi et al. [42] found that CKD impaired ischemia-induced angiogenesis and reperfusion in a model of hind-limb ischemia in subtotally nephrectomized rats. They suspected that the increased concentration of nitric oxide inhibitor (asymmetric dimethylarginine) and decreased expression of VEGF and its receptors in skeletal muscles was associated with impaired angiogenesis [42]. These data seem to coincide with our results. The significantly reduced expression of HIF-1 $\alpha$ at mRNA and protein levels as well as VEGF-A and VEGFR-1 and -2 in the CKD5/6 group may be responsible for a large deficit of capillaries in MG observed in the previous study. In ML, mRNA expression of HIF- $1 \alpha$, VEGF-A and its receptors did not differ compared to controls, while increased levels of HIF-1 $\alpha$ protein were observed. However, in a previous study, we showed only a moderate loss of capillaries, which may depend on endothelial dysfunction. A systemic inflammatory response is thought to be a key factor in the endothelium dysfunction observed in CKD. MCP-1-recruiting macrophages have been established as a marker of endothelial injury and inflammatory processes in the vessel wall. The concentration of MCP-1 increased with 
the progression of CKD in our study. Many investigations also confirmed that enhanced expression of AGE receptors on monocytes in CKD might cause monocyte-mediated systemic inflammation. Inflammatory mediators have a negative impact on the integrity of the endothelium, which leads to impaired communication between adjacent endothelial cells. A study by Bagi et al. [43] performed on rats in the early stages of renal failure revealed reduced dilatation of arterioles isolated from gracilis muscle induced by NO. These data suggested that vascular endothelial function becomes abnormal upon exposure to constituents of uremic plasma through impaired signalling by NO.

In conclusion, we put forward a hypothesis that diminished mRNA and protein levels of HIF- $1 \alpha$ in locomotor skeletal muscle of uremic animals could be responsible for impaired angiogenesis and sarcopenia and could lead to uremic myopathy syndrome. We suspect that these disturbances could be secondary to increased oxidative and carbonyl stress (AGEs), inflammation and hyperhomocysteinemia. Postural skeletal muscle with more oxidative fibers can be protected from these disturbances through the increased expression of iNOS and NO-dependent HIF-1 $\alpha$ stabilization. Physical activity probably alleviates some signs of uremic myopathy syndrome, as it was indicated that muscle stretching increases HIF- $1 \alpha$ and -2 expression in skeletal muscle [44]. Further research on the role of HIF-1 $\alpha$ in CKD-related sarcopenia might help discover a new class of drugs for uremic myopathy syndrome. FG-2216, which is an HIF $\alpha$ prolyl hydroxylase inhibitor, is the first substance that has been used in clinical trials as an HIF-activating antianemia drug. Preliminary data demonstrated that pharmacological manipulation of the HIF- $1 \alpha$ system can stimulate endogenous erythropoietin production even in anephric patients [45]. Whether or not it could constitute a cure for structural disturbances of locomotor skeletal muscle observed in uremic myopathy syndrome is still an open question. Recognizing the limitations of our research, the exact role of HIF-1 $\alpha$ in the development of uremic myopathy syndrome needs further investigation. In particular, HIF-1 $\alpha$ immunostaining and the DNA-binding activity of HIF- $1 \alpha$, as well as expression of the HIF-2 gene, need to be tested in further experiments.

\section{Acknowledgements}

This work was supported by grants from Nicolaus Copernicus University (numbers 02/2010 and 03/2010).

Special thanks are expressed to Mrs. Maria Szpila and Dr. hab Zenon Grabarczyk for correcting the English language of the manuscript.

\section{Disclosure Statement}

The authors declare no competing interests.

\section{References}

1 Johansen KL, Doyle J, Sakkas GK, KentBraun JA: Neural and metabolic mechanisms of excessive muscle fatigue in maintenance hemodialysis patients. Am J Physiol Regul Integr Comp Physiol 2005;289:R805R813.

-2 Lombard JH, Frisbee JC, Greene AS, Hudetz AG, Roman RJ, Tonellato PJ: Microvascular flow and tissue $\mathrm{PO}(2)$ in skeletal muscle of chronic reduced renal mass hypertensive rats. Am J Physiol Heart Circ Physiol 2000; 279:H2295-H2302.

3 Zhang L, Rajan V, Lin E, Hu Z, Han HQ, Zhou X, Song Y, Min H, Wang X, Du J, Mitch WE: Pharmacological inhibition of myostatin suppresses systemic inflammation and muscle atrophy in mice with chronic kidney disease. FASEB J 2011;25:1653-1663.

Decreased Contents of HIF-1 $\alpha$ in Rat Locomotor Skeletal Muscle
4 Marrades RM, Roca J, Campistol JM, Diaz O, Barberá JA, Torregrosa JV, Masclans JR, Cobos A, Rodríguez-Roisin R, Wagner PD: Effects of erythropoietin on muscle $\mathrm{O}_{2}$ transport during exercise in patients with chronic renal failure. J Clin Invest 1996;97:20922100.

5 Sala E, Novszewski EA, Campistol JM: Impaired muscle oxygen transfer in patients with chronic renal failure. Am J Physiol 2001;280:R1240-R1248.

-6 Flisiński M, Brymora A, Elminowska-Wenda G, Bogucka J, Walasik K, Stefańska A, Odrowaz-Sypniewska G, Manitius J: Influence of different stages of experimental chronic kidney disease on rats locomotor and postural skeletal muscles microcirculation. Ren Fail 2008;30:443-451.

7 Marrades RM, Alonso J, Roca J, González de Suso JM, Campistol JM, Barberá JA, Diaz O, Torregrosa JV, Masclans JR, Rodríguez-Roi$\sin \mathrm{R}$, Wagner PD: Cellular bioenergetics after erythropoietin therapy in chronic renal failure. J Clin Invest 1996;97:2101-2110. $\checkmark 8$ Semenza GL: HIF-1, O(2), and the 3 PHDs: how animal cells signal hypoxia to the nucleus. Cell 2001;107:1-3.

-9 Nangaku M: Chronic hypoxia and tubulointerstitial injury: a final common pathway to end-stage renal failure. J Am Soc Nephrol 2006;17:17-25.

10 Huang LE, Gu J, Schau M, Bunn HF: Regulation of hypoxia-inducible factor 1alpha is mediated by an $\mathrm{O}_{2}$-dependent degradation domain via the ubiquitin-proteasome pathway. Proc Natl Acad Sci USA 1998;95:7987-7992.

11 Mounier R, Pedersen BK, Plomgaard P: Muscle-specific expression of hypoxia-inducible factor in human skeletal muscle. Exp Physiol 2010;95:899-907.

12 Pisani DF, Dechesne CA: Skeletal muscle HIF1alpha expression is dependent on muscle fiber type. J Gen Physiol 2005;126:173-178. 
13 Yoon D, Pastore YD, Divoky V, Liu E, Mlodnicka AE, Rainey K, Ponka P, Semenza GL, Schumacher A, Prchal JT: HIF-1 $\alpha$-deficiency results in dysregulated EPO signaling and iron homeostasis in mouse development. J Biol Chem 2006;281:25703-25711.

-14 Hagström L, Agbulut O, El-Hasnaoui-Saadani R, Marchant D, Favret F, Richalet JP, Beaudry M, Launay T: Epo is relevant neither for microvascular formation nor for the new formation and maintenance of mice skeletal muscle fibres in both normoxia and hypoxia. J Biomed Biotechnol 2010;2010:137817.

-15 Ameln H, Gustafsson T, Sundberg CJ, Okamoto K, Jansson E, Poellinger L, Makino Y: Physiological activation of hypoxia inducible factor-1 in human skeletal muscle. FASEB J 2005;19:1009-1011.

- 16 Vogt M, Puntschart A, Geiser J, Zuleger C, Billeter R, Hoppeler H: Molecular adaptations in human skeletal muscle to endurance training under simulated hypoxic conditions. J Appl Physiol 2001;91:173-182.

17 Munch G, Keis R, Wessels A, Riederer P, Bahner U, Heidland A, Niwa T, Lemke HD, Schinzel R: Determination of advanced glycation end products in serum by fluorescence spectroscopy and competitive ELISA. Eur J Clin Chem Clin Biochem 1997;35:669677.

18 User Bulletin 2 - ABI PRISM 7700 Sequence Detection System. Foster City, Applied Biosystems, 1997 (updated 10/2001).

19 Drewa T, Joachimiak R, Kaznica A, Flisinski M, Brymora A, Manitius J: Bone marrow progenitors from animals with chronic renal failure lack capacity of in vitro proliferation. Transplant Proc 2008;40:1668-1673.

-20 Natarajan R, Fisher BJ, Fowler AA 3rd: Regulation of hypoxia inducible factor-1 by nitric oxide in contrast to hypoxia in microvascular endothelium. FEBS Lett 2003;549:99104.

21 Booth FW, Baldwin KM: Muscle plasticity: energy demand and supply processes; in: Handbook of Physiology: Integration of Motor, Circulatory, Respiratory, and Metabolic Control during Exercise. Bethesda, American Physiological Society, 1996, pp 10751123.

22 Anderson EJ, Neufer PD: Type II skeletal myofibers possess unique properties that potentiate mitochondrial $\mathrm{H}(2) \mathrm{O}(2)$ generation. Am J Physiol Cell Physiol 2006;290:C844C851.
Pialoux V, Mounier R, Brown AD, Steinback CD, Rawling JM, Poulin MJ: Relationship between oxidative stress and HIF-1 $\alpha$ mRNA during sustained hypoxia in humans. Free Radic Biol Med 2009;46:321-326.

24 Yu Z, Li P, Zhang M, Hannink M, Stamler JS, Yan Z: Fiber type-specific nitric oxide protects oxidative myofibers against cachectic stimuli. PLoS One 2008;3:e2086.

25 Palmer LA, Semenza GL, Stoler MH, Johns RA: Hypoxia induces type II NOS gene expression in pulmonary artery endothelial cells via HIF-1. Am J Physiol Lung Cell Mol Physiol 1998;274:L212-L219.

26 Vaux EC, Metzen E, Yeates KM, Ratcliffe PJ: Regulation of hypoxia inducible factor is preserved in the absence of a functioning $\mathrm{mi}$ tochondrial respiratory chain. Blood 2001; 98:296-302.

27 Sandau KB, Fandrey J, Brüne B: Accumulation of HIF-1alpha under the influence of nitric oxide. Blood 2001;97:1009-1015.

28 Hagen T, Taylor CT, Lam F, Moncada S: Redistribution of intracellular oxygen in hypoxia by nitric oxide: effect on HIFlalpha. Science 2003;302:1975-1978.

29 Wellman TL, Jenkins J, Penar PL, Tranmer B, Zahr R, Lounsbury KM: Nitric oxide and reactive oxygen species exert opposing effects on the stability of hypoxia-inducible factor-1alpha (HIF-1alpha) in explants of human pial arteries. FASEB J 2004;18:379-381.

30 Köhl R, Zhou J, Brüne B: Reactive oxygen species attenuate nitric-oxide-mediated hypoxia-inducible factor-1alpha stabilization. Free Radic Biol Med 2006;40:1430-1442

- 31 Thomas DD, Ridnour LA, Espey MG, Donzelli S, Ambs S, Hussain SP, Harris CC, DeGraff W, Roberts DD, Mitchell JB, Wink DA: Superoxide fluxes limit nitric oxide-induced signaling. J Biol Chem 2006;281:2598425993.

32 Papandreou I, Cairns RA, Fontana L, Lim AL, Denko NC: HIF-1 mediates adaptation to hypoxia by actively downregulating mitochondrial oxygen consumption. Cell Metab 2006;3:187-197.

33 Brüne B, Zhou J: Nitric oxide and superoxide: interference with hypoxic signaling. Cardiovasc Res 2007;75:275-282.

34 Shah AJ, Sahgal V, Quintanilla AP, Subramani V, Singh H, Hughes R: Muscle in chronic uremia - a histochemical and morphometric study of human quadriceps muscle biopsy. Clin Neuropathol 1983;2:83-89.

-35 Mason SD, Howlett RA, Kim MJ, Olfert IM, Hogan MC, McNulty W, Hickey RP, Wagner PD, Kahn CR, Giordano FJ, Johnson RS: Loss of skeletal muscle HIF-1 $\alpha$ results in altered exercise endurance. PLoS Biol 2004;2:e288.
6 Kopple JD, Wang H, Fournier M, Storer T, Zhang SM, Song HY, Lewis M: Transcriptional levels of growth factors in skeletal muscle of maintenance hemodialysis patients. J Ren Nutr 2006;16:212-215.

37 Himmelfarb J, Stenvinkel P, Ikizler TA, Hakim RM: The elephant in uremia: oxidant stress as a unifying concept of cardiovascular disease in uremia. Kidney Int 2002;62: 1524-1538.

38 Lim PS, Cheng YM, Wei YH: Large-scale mitochondrial DNA deletions in skeletal muscle of patients with end-stage renal disease. Free Radic Biol Med 2000;29:454-463.

39 Ingrosso D, Cimmino A, Perna AF, Masella L, De Santo NG, De Bonis ML, Vacca M, D’Esposito M, D’Urso M, Galletti P, Zappia V: Folate treatment and unbalanced methylation and changes of allelic expression induced by hyperhomocysteinaemia in patients with uraemia. Lancet 2003;361:16931699.

40 Dery MA, Michaud MD, Richard DE: Hypoxia-inducible factor 1 : regulation by hypoxic and non-hypoxic activators. Int J Biochem Cell Biol 2005;37:535-540.

-41 Pajusola K, Künnapuu J, Vuorikoski S, Soronen J, André H, Pereira T, Korpisalo P, YläHerttuala S, Poellinger L, Alitalo K: Stabilized HIF- $1 \alpha$ is superior to VEGF for angiogenesis in skeletal muscle via adenoassociated virus gene transfer. FASEB J 2005; 19:1365-1367.

42 Jacobi J, Porst M, Cordasic N, Namer B, Schmieder RE, Eckardt KU, Hilgers KF: Subtotal nephrectomy impairs ischemia-induced angiogenesis and hindlimb reperfusion in rats. Kidney Int 2006;69:2013-2021.

43 Bagi Z, Hamar P, Antus B, Rosivall L, Koller A: Chronic renal failure leads to reduced flow-dependent dilatation in isolated rat skeletal muscle arterioles due to lack of $\mathrm{NO}$ mediation. Kidney Blood Press Res 2003;26: $19-26$.

44 Milkiewicz M, Doyle JL, Fudalewski T, Ispanovic E, Aghasi M, Haas TL: HIF-1alpha and HIF-2alpha play a central role in stretch-induced but not shear-stress-induced angiogenesis in rat skeletal muscle. J Physiol 2007; 583:753-766.

-45 Bernhardt WM, Wiesener MS, Scigalla P, Chou J, Schmieder RE, Günzler V, Eckardt $\mathrm{KU}$ : Inhibition of prolyl hydroxylases increases erythropoietin production in ESRD. J Am Soc Nephrol 2010;21:2151-2156. 